\title{
OS CORREDORES EXCLUSIVOS DE ÔNIBUS: QUAL SUA IMPORTÂNCIA E SEU IMPACTO NA CIDADE DE CURITIBA
}

Ricardo Massulo Albertin ${ }^{1}$; Anderson Camargo ${ }^{2}$; Antônio Lima ${ }^{3}$; Hugo Gabriel Fernandes Viotto ${ }^{4}$; Frederico Fonseca da Silva $^{5}$; Fábio Henrique Soares Angeoletto ${ }^{6}$.

1 - Geógrafo. Mestre em Engenharia Urbana. Doutor em análise ambiental. É Consultar Ambiental e atua como professor de IES - em cursos de graduação e pós-graduação. É coordenador de Pesquisa e Extensão da Faculdade de Arquitetura e Engenharias (FEITEP)

2 - Assistente administrativo na empresa Centro Integrado de Oncologia de Curitiba. Instituição (IES): Instituto Federal do Paraná

3 - Técnico em Transporte pela URBS-Urbanização de Curitiba S/A, Atuou também na iniciativa privada como Supervisor de Tráfego empresa Araucária Transporte Coletivo Ltda. e Controlador de Tráfego na empresa Viação Mercês Ltda.

4 - Possui graduação (bacharelado) em Engenharia Civil pela Faculdade de Engenharia e Inovação Técnico Profissional, Maringá-PR (2017). Pós graduado em Docência do Ensino Superior Pela Faculdade São Braz, Campus Apucarana, PR (2018) e pós-graduando em Engenharia de Segurança do Trabalho pela Universidade Estadual de Maringá (UEM), Campus Maringá, PR (2018).

5 - Possui Graduação em Engenharia Agronômica pela Universidade Federal da Paraíba (1985); Mestrado em Agronomia pela UEM - Universidade Estadual de Maringá (2002); e, Doutorado em Produção Vegetal também pela UEM - Universidade Estadual de Maringá (2006). Atualmente é professor e pesquisador do Instituto Federal do Paraná (IFPR).

6 - Bacharel e Licenciado em Ciências Biológicas pela Universidade Estadual de Maringá. Mestre em Arquitetura e Urbanismo pela Universidade Federal da Bahia. Doutor em Ecologia pela Universidade Autônoma de Madri.

\section{Resumo}

A crescente procura por meios de transporte público que sejam eficientes e de qualidade nos centros urbanos reitera a necessidade de novos e maiores investimentos pela iniciativa pública no setor da mobilidade urbana. Dado exposto, o presente estudo consiste em analisar quais os possíveis impactos que a implantação de faixas exclusivas causa na cidade de Curitiba (PR). Em primeiro momento o estudo utiliza-se de revisão bibliográfica que permite verificar aspectos técnicos, baseando-se em obras que visam dar melhor entendimento sobre o tema da forma em que são apresentados no contexto histórico. Na sequência buscou-se realizar um estudo quali-quantitativo que visam dar sustentação ao tema proposto por meio de estudos bibliográficos e levantamento de dados. O estudo buscou analisar se houve ganho de tempo em duas faixas exclusivas que foram implantadas na cidade de Curitiba, sendo elas nas ruas XV de Novembro e Rua Marechal Deodoro, trecho entre Rua João Negrão e Alameda Doutor Muricy. A análise permitiu identificar se houve um impacto em linhas do transporte coletivo que utilizam os trechos mencionados. Fora possível evidenciar que os trechos ainda carecem de novas intervenções para que haja um impacto melhor na mobilidade urbana da cidade.

Palavras-chaves: Faixas Exclusivas; Mobilidade Urbana; Transporte Coletivo. 


\section{THE EXCLUSIVE BUS RIDERS: WHAT IS YOUR IMPORTANCE AND ITS IMPACT ON THE CITY OF CURITIBA (BRAZIL)}

Ricardo Massulo Albertin ${ }^{1}$; Anderson Camargo ${ }^{2}$; Antônio Lima ${ }^{3}$; Hugo Gabriel Fernandes Viotto ${ }^{4}$; Frederico Fonseca da Silva $^{5}$; Fábio Henrique Soares Angeoletto ${ }^{6}$.

1 - Geógrafo. Mestre em Engenharia Urbana. Doutor em análise ambiental. É Consultar Ambiental e atua como professor de IES - em cursos de graduação e pós-graduação. É coordenador de Pesquisa e Extensão da Faculdade de Arquitetura e Engenharias (FEITEP)

2 - Assistente administrativo na empresa Centro Integrado de Oncologia de Curitiba. Instituição (IES): Instituto Federal do Paraná

3 - Técnico em Transporte pela URBS-Urbanização de Curitiba S/A, Atuou também na iniciativa privada como Supervisor de Tráfego empresa Araucária Transporte Coletivo Ltda. e Controlador de Tráfego na empresa Viação Mercês Ltda.

4 - Possui graduação (bacharelado) em Engenharia Civil pela Faculdade de Engenharia e Inovação Técnico Profissional, Maringá-PR (2017). Pós graduado em Docência do Ensino Superior Pela Faculdade São Braz, Campus Apucarana, PR (2018) e pós-graduando em Engenharia de Segurança do Trabalho pela Universidade Estadual de Maringá (UEM), Campus Maringá, PR (2018).

5 - Possui Graduação em Engenharia Agronômica pela Universidade Federal da Paraíba (1985); Mestrado em Agronomia pela UEM - Universidade Estadual de Maringá (2002); e, Doutorado em Produção Vegetal também pela UEM - Universidade Estadual de Maringá (2006). Atualmente é professor e pesquisador do Instituto Federal do Paraná (IFPR).

6 - Bacharel e Licenciado em Ciências Biológicas pela Universidade Estadual de Maringá. Mestre em Arquitetura e Urbanismo pela Universidade Federal da Bahia. Doutor em Ecologia pela Universidade Autônoma de Madri.

\section{Abstract}

The growing demand for efficient and quality public transport in urban centres reiterates the need for new and greater investments by the public initiative in the urban mobility sector. In view of the above, the present study consists of analyzing the possible impacts that the implantation of exclusive bands provokes in the City of Curitiba (PR). Firstly, the study uses a bibliographic review that allows to verify the technical aspects, based on works that aim to give better understanding about the theme in a form that is presented in the historical context. Subsequently, a qualitative-quantitative study was carried out to subsidize the proposed theme through bibliographical studies and data collection. The study sought to analyze whether there was a time gain in two exclusive tracks that were implanted in the city of Curitiba, being them on November 15th and on Marechal Deodoro Street, a stretch between Rua João Negrão and the Dr. Muricy Mall. The analysis allowed to identify whether there was an impact on the collective transport lines that use the mentioned passages. It was possible to highlight that the excerpts still lack new interventions so that there is a better impact on urban mobility of the city.

Keywords: Exclusive Tracks; Urban Mobility; Public Transportation. 


\section{INTRODUÇÃO}

A mobilidade urbana é de grande relevância nas pequenas e grandes cidades, logo que, podem influenciar diretamente a qualidade de vida populacional. Devido a esta demanda, faz-se necessário um sistema de transporte público que seja eficiente e de qualidade, no qual, os modais devem atender a satisfação dos usuários. Neste segmento, o princípio da liberdade é fundamental, isto é, todo cidadão tem seu direito de ir e vir de modo que seja exequível realizar suas atividades cotidianas sem grandes interferências em seu trajeto (SILVA, 2015).

Todavia, há um desafio na gestão pública para que exista uma qualidade de vida em relação à mobilidade urbana. Desta forma, às ações do poder público devem ser análogas aos meios de locomoção que incentivem o transporte coletivo, principalmente de modo a possibilitar a substituição do automóvel por este modal (BRASIL, 2007).

Segundo Gomide (1992), na sociedade capitalista, o deslocamento de pessoas se mostram de fundamental importância, pois se trata de condição necessária para a concretização das relações econômicas e sociais, fundamentais à reprodução e a existência deste próprio modo de produção. Sendo assim, a utilização do transporte público urbano é de grande relevância para a sociedade, que, diariamente necessitam se deslocar aos seus destinos de forma eficaz e fluida.

Deste modo, a mobilidade urbana tem como um dos seus principais temas os transportes coletivos urbanos, que são um dos principais meios de desenvolvimento das cidades. Dentro deste contexto, cada vez mais tem-se procurado por soluções que tornem o transporte coletivo urbano atrativo o suficiente a fim de atender ao cidadão satisfatoriamente.

Entretanto para atingir este nível de excelência do transporte de massa devem ser avaliados os ônibus e seus corredores exclusivos. Estes geram benefícios a sociedade de ordem econômica, possibilitam maior otimização do tempo de viagem e minimizam os impactos ao meio ambientem logo que, de forma simplória, promovem a redução da emissão de gases do efeito estufa. 
Desta forma, o estudo objetivou-se em analisar o ganho de tempo dos corredores implantados na cidade de Curitiba. Para isto, foram coletados dados da URBS para o desenvolvimento da pesquisa e conclusão final a respeito desta medida relacionada à mobilidade urbana.

\section{FUNDAMENTAÇÃO TEÓRICA}

\subsection{Histórico do transporte no Brasil}

O primeiro modelo de ônibus chegou ao Brasil, na cidade do Rio de Janeiro (RJ), por volta do século XIX e foi movido por tração animal. Com a vinda deste veículo criou-se a primeira companhia de transporte no país onde introduziu as primeiras linhas operantes. Com o passar do tempo viu-se a necessidade de aprimorar seus serviços de transporte e criar modelos de maior eficiência para comportar a população, foi onde ocorreu a substituição destes veículos de tração animal para a implantação mini locomotivas (STIEL, 1984).

Por seu modo, estes veículos deslocavam-se inicialmente sob trilhos de tração a vapor e, posteriormente, sob tração elétrica, e eram modelos para o crescimento das demais companhias que surgiram ao longo do território nacional. Segundo Stiel (1984), a criação elétrica nos veículos serviu de incentivo para o bonde elétrico o qual proporcionou o aumento da capacidade de locomoção e o desenvolvimento das estradas de ferro.

Barat (1975), menciona que o bonde elétrico ficou defasado com o decorrer do tempo e caiu em desuso, o que deu margem para a criação do auto-ônibus no cenário urbano brasileiro. Sabendo da importância desse meio de transporte no país, a mobilidade de locomoção passou a enfrentar concorrência do carro como meio de transporte, e a partir da década de 1960, o Brasil criou um modelo de mobilidade urbana que privilegiava o automóvel como primeira opção, de acordo com Freire et al. (2010). 


\subsection{Histórico do transporte de Curitiba}

As transformações de Curitiba tiveram início nos anos 40 e seguiu o planejamento urbano do arquiteto francês chamado de Alfred Donat Agache que desenvolveu o primeiro plano diretor da cidade, e ficou conhecido como Plano Agache. Este plano refletia as características no desenvolvimento de planejamento de cidades europeias e foi desenvolvido em diversas cidades brasileiras (AUGUSTO, 2015).

Ainda para Augusto (2015), este desenvolvimento tinha por característica o projeto da forma radial urbana com vias circulares que ligavam o crescimento ao redor do centro. Como consequência, o crescimento ordenado da cidade de Curitiba esteve diretamente vinculado a este processo.

Partindo do princípio da revolução no transporte coletivo de Curitiba, o aumento constante na população na década de 1970 fora uma preocupação imediata ao poder público deste período. Neste cenário, a população clamava para que houvesse uma melhora na qualidade dos serviços prestados pela prefeitura a toda sociedade (URBS, 2012).

Para o cumprimento destes anseios, todos os bairros da capital paranaense começaram a suprir esta demanda pelo transporte público. Em 1974 foram criados os primeiros corredores exclusivos de ônibus do mundo, sistema este denominado como Sistema de Ônibus Expresso, que por sua vez possibilitou para que os coletivos circulassem em vias exclusivas, isto é, separadas dos demais automóveis (URBS, 2012).

A criação das canaletas exclusivas do transporte coletivo buscou sanar problemas enfrentados na mobilidade urbana na cidade e reorientar a expansão e o crescimento que qualificava a circulação do transporte urbano. De acordo com Miranda (2010), havia um novo plano para que houvesse uma melhora na distribuição da infraestrutura dos edifícios, e substituísse a conformação radial de Curitiba. 
Para que houvesse à implantação de um novo modal de transporte foi necessária a implantação de um modelo de sistema viário, que visasse a integralização do transporte coletivo ao zoneamento da cidade (Figura 1). Logo, começou-se a utilizar um sistema definido por eixos estruturais, no qual, havia a malha urbana pré-existente de duas vias paralelas de tráfego rápido em sentindo único, direcionadas uma em sentido bairro e ao sentido centro, estas foram definidas como um conjunto denominado de sistema trinário (OBA, 2004).

Figura 1 - Esquema do sistema trinário

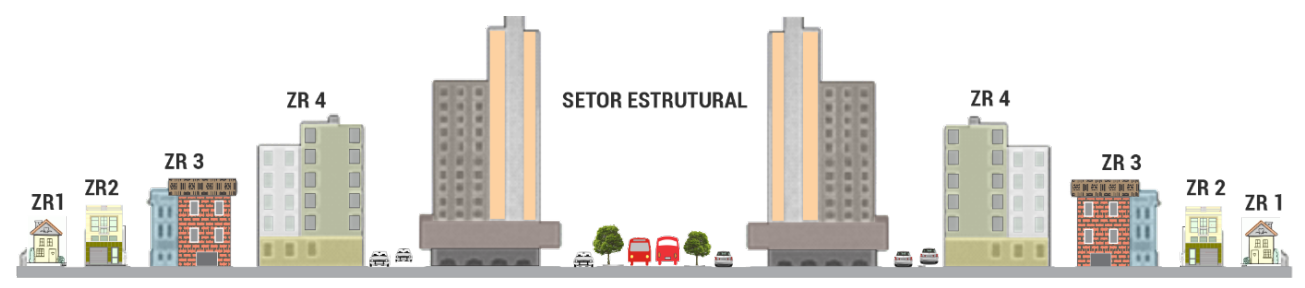

Fonte: IPPUC (s.a)

Os eixos estruturais deram origem ao sistema trinário de Curitiba. Este modelo foi dividido por um conjunto de três vias, em que, a via central fora designada a atender o tráfego lento e acomodar as vias exclusivas de ônibus e comércio, enquanto que, as vias externas foram destinadas ao tráfego rápido de automóveis (MIRANDA, 2010).

\subsection{Sistema Trinário}

O sistema trinário é composto por elementos referenciais dos eixos estruturais de desenvolvimento. Os corredores exclusivos do transporte desempenham um papel fundamental, logo que ordenam o crescimento linear da cidade em diversos aspectos, assim como melhoram a infraestrutura urbana, priorizam a instalação de equipamentos urbanos e reduzem o tempo de viagem dos usuários que se deslocava até a região central de Curitiba (URBS, 2018).

Perfazem o sistema trinário outras duas vias paralelas que são situadas à esquerda e a direita da rua principal. Ambas são vias de trânsito rápido, todavia conduzem o tráfego de veículos em sentidos 
diferentes, a primeira no sentido centro-bairro e a segunda no sentido bairro centro (PMC, 2015).

Outra parte adjacente deste sistema é a questão de sua via central que proporciona a circulação de linhas expressas e constituem de mais duas vias lentas para o acesso as atividades lindeiras. Esta medida representa ganhos consideráveis na questão da velocidade, conforme ilustrado na Figura 2:

Figura 2 - PlanMobi Curitiba
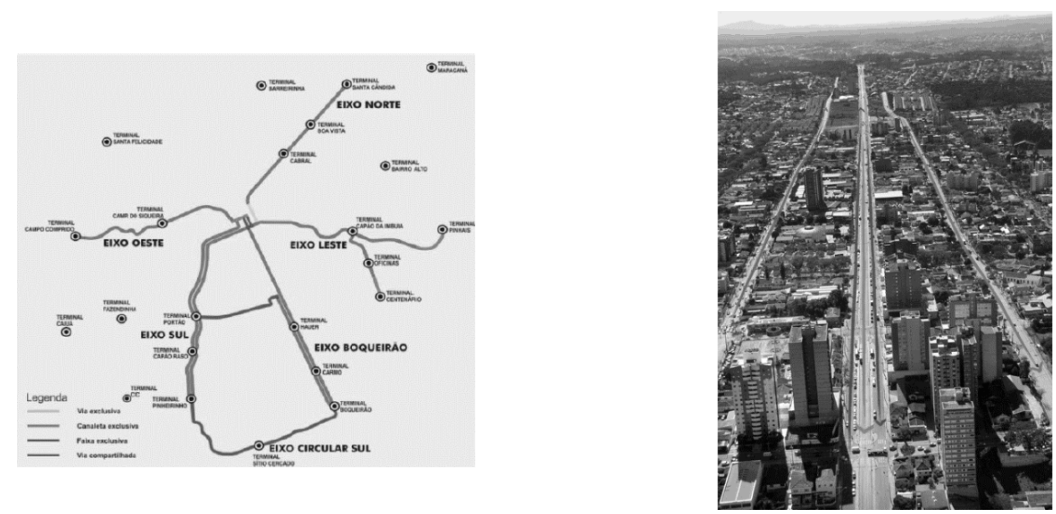

Fonte: IPPUC (2008)

\subsection{Bus Rapid Transit (BRT)}

Para Augusto (2015), o BRT é um sistema que proporciona uma qualidade de vida em relação ao conforto a mobilidade urbana e sua eficiência. Este sistema não realiza o compartilhamento com os automóveis, o que influencia diretamente na eficiência das viagens para os usuários.

O BRT pode se comparar como o sistema mais próximo de veículos leves sobre trilhos (VLT), sendo que este sistema tem um custo de 4 a 20 vezes menor que um sistema de VLT e, pode-se chegar até 100 vezes menos que o custo de um metrô. Entretanto, este sistema carece de investimentos em relação a sua infraestrutura, como às instalações de estações, benfeitorias de integrações, utilidade pública e paisagismo (BRASIL, 2007). 
Para Silva e Anna (2006), este sistema permite que o ônibus possa operar em corredores exclusivos com ou sem a segregação física. As vias ficam exclusivamente dedicadas ao trafego dos coletivos, fato este que possibilita um ganho expressivo em termos de mobilidade urbana, logo que promove uma melhora no desempenho de velocidade e fluidez do transito.

O sistema BRT (Figura 3) pode contribuir nas questões ambientais, como na redução da emissão de dióxido de carbono $\mathrm{CO} 2$, logo que há uma otimização em suas viagens, o que acarreta em uma diminuição no uso de combustível (ALLIARDI, 2016).

Figura 3 - BRT, Canaleta exclusiva do transporte coletivo e seus eixos estruturais.

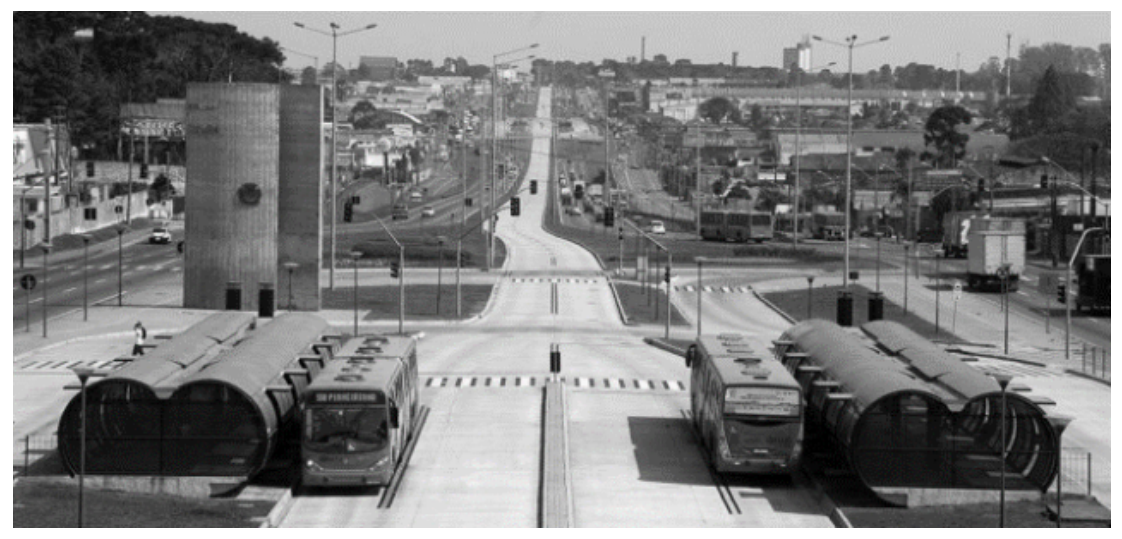

Fonte: Gazeta do Povo (2010).

\subsection{Estrutura do transporte coletivo de Curitiba}

Segundo o PlanMobi de Curitiba o conceito básico da estrutura do transporte coletivo de Curitiba deve estar em harmonia com o planejamento urbano da cidade. Sua inclusão com a rede integrada possibilita maior facilidade ao usuário, logo que o mesmo pode realizar o transbordo entre estações tubos e terminais sem o pagamento de nova tarifa (IPPUC, 2008).

As características das frotas de ônibus de Curitiba são compostas por 9 categorias de linhas, conforme ilustrado na Figura 4. Essas linhas atendem Curitiba e parte da região metropolitana e as frotas são definidas como: Expresso Ligeirão, Expresso Parador, Linha Direta Interbairros, Alimentadores, Troncal, Convencional, Circular Centro e Turismo que abrangem um total de 1226 em frota operante, atendendo 251 linhas, segundo o estudo feito em 2018 (URBS,2018). 
Figura 4 - Composição da frota

\begin{tabular}{|c|c|c|c|c|c|c|}
\hline \multicolumn{7}{|c|}{ COMPOSIÇÃO DA FROTA 2018} \\
\hline \multicolumn{7}{|c|}{ RIT - REDE INTEGRADA DE TRANSPORTE } \\
\hline $\begin{array}{l}\text { Categoria de } \\
\text { Linhas }\end{array}$ & \multicolumn{2}{|r|}{ Tipos de Veículo } & \multirow{2}{*}{$\begin{array}{c}\text { Capacidade } \\
\text { dos Veiculos } \\
250 \\
250\end{array}$} & \multicolumn{2}{|c|}{$\begin{array}{l}\text { Frota Operante } \\
\text { Subtotal Total }\end{array}$} & \multirow{2}{*}{$\begin{array}{c}\text { Quantidade } \\
\text { de Linhas }\end{array}$} \\
\hline $\begin{array}{l}\text { EXPRESSO } \\
\text { LIGEIRÁO }\end{array}$ & BIARTICULADO & Coll & & 44 & 44 & \\
\hline \multirow{2}{*}{ EXPRESSO } & BAARTICULADO & " & 230/250 & 97 & \multirow{2}{*}{127} & \multirow{2}{*}{05} \\
\hline & ARTICULADO & 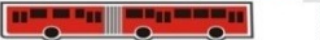 & 170 & 30 & & \\
\hline \multirow{2}{*}{ LINHA DIRETA } & ARTICULADO & 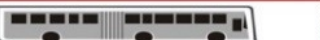 & 150 & 39 & \multirow{2}{*}{223} & \multirow{2}{*}{15} \\
\hline & PADRON & 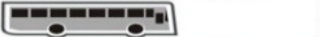 & 110 & 184 & & \\
\hline \multirow{3}{*}{ INTERBAIRROS } & ARTICULADO & II'0-"II & 140 & 92 & \multirow{3}{*}{103} & \multirow{3}{*}{08} \\
\hline & PADRON & "110-|1 & 100 & 1 & & \\
\hline & HIBRIDO & ت110-11 & 79 & 10 & & \\
\hline \multirow{3}{*}{ ALIMENTADOR } & ARTICULADO & III:-"II : & 140 & 71 & \multirow{3}{*}{424} & \multirow{3}{*}{129} \\
\hline & сомим & 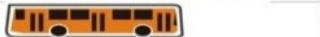 & 85 & 324 & & \\
\hline & \multicolumn{2}{|c|}{ MICRO ESPECIAL } & 70 & 29 & & \\
\hline \multirow{4}{*}{ TRONCAL } & ARTICULADO & 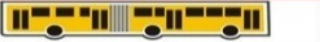 & 140 & 5 & \multirow{4}{*}{80} & \multirow{4}{*}{15} \\
\hline & сомим & 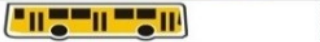 & 85 & 62 & & \\
\hline & HIBRIDO & 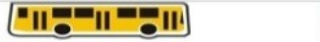 & 79 & 10 & & \\
\hline & \multicolumn{2}{|c|}{ MICRO ESPECAAL } & 70 & 3 & & \\
\hline \multirow{4}{*}{ CONVENCIONAL } & сомим & 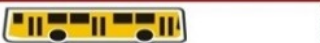 & 85 & 99 & \multirow{4}{*}{214} & \multirow{4}{*}{74} \\
\hline & HIBRIDO & 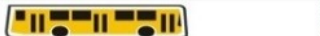 & 79 & 10 & & \\
\hline & \multicolumn{2}{|c|}{ MICRO ESPECIAL } & 70 & 102 & & \\
\hline & MICRO & 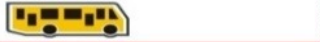 & 40 & 3 & & \\
\hline CIRCULAR & MICRO & 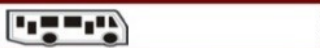 & 40 & 5 & 5 & 01 \\
\hline TURISMO & DOUBLE-DECK & 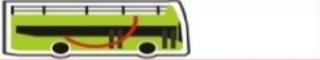 & 65 & 6 & 6 & 01 \\
\hline & & & TOTAL & & & 251 \\
\hline
\end{tabular}

Fonte: URBS (2018).

\subsection{Implantação de novas faixas exclusivas}

Seguindo o modelo de corredores exclusivos para ônibus já existente na cidade (Figura 5), Curitiba inovou em criar novas faixas que visam ganhar uma melhoria do ganho de tempo no transporte coletivo. Tais faixas são incorporadas ao trânsito da cidade gerando uma melhora no deslocamento do transporte de passageiros. Ao todo são sete faixas exclusivas de uso do transporte coletivo localizadas nas ruas XV de Novembro, Marechal Deodoro, Conselheiro Laurindo, Des. Westphalen, General Mario Tourinho, André de Barros e Alfredo Brunfen e somam no total oito quilômetros de extensão que beneficiam 80 linhas e mais de 309 mil usuários por dia (URBS, 2018). 
Figura 5 - Faixas exclusivas implementadas.

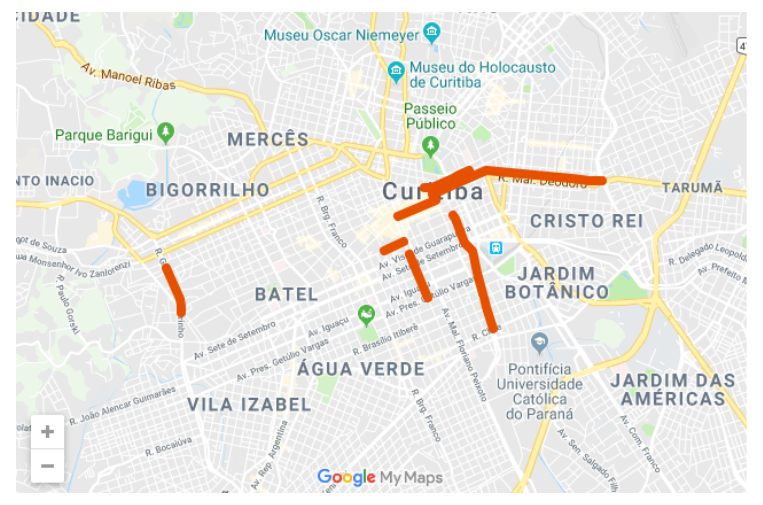

Fonte: Google Earth (2019).

\section{PROCEDIMENTOS METODOLÓGICOS}

Nesta etapa do estudo, a pesquisa objetivou-se em realizar um levantamento bibliográfico, de referências teóricas correlacionadas a temática, de modo a fundamentar à análise dos dados obtidos. Por sua vez, a etapa quantitativa buscou realizar uma comparação dos dados fornecidos pela URBS, isto é, em relação a eficiência no ganho de tempo do transporte coletivo em trechos de faixas exclusivas recentemente implantadas.

Devido ao amplo número de corredores e faixas exclusivas de transportes foram selecionadas duas faixas implementadas recentemente na cidade de Curitiba. Sendo assim, fora possível realizar uma análise crítica e detalhada do estudo, de modo a verificar se de fato houve ou não melhoras nas alterações realizadas nos trechos estudados.

As faixas exclusivas escolhidas foram: Rua XV de novembro; e, Rua Marechal Deodoro, trecho entre Rua João Negrão e Alameda Doutor Muricy, em função do elevado fluxo de veículos onde, a campo, pode-se fazer essas medições. As descrições e a análise críticas dos parâmetros foram fundamentados conforme recomendações da URBS.

Para a coleta de resultados, foram considerados os tempos de percurso, bem como quantidades de embarques e desembarques realizados antes e após a implantação das faixas. Todos os dados foram 
coletados pelo SBE - Sistema de Bilhetagem Eletrônica, software implantado para sistema de controle embarcado nos ônibus no município de Curitiba.

\section{RESULTADOS E DISCUSSÃO}

\subsection{Características das faixas das ruas XV e Deodoro}

Curitiba possui $8 \mathrm{Km}$ de faixas exclusivas em vias que fazem a ligação entre o centro da cidade até os bairros afastados de sua região. Circulam diariamente 80 linhas em toda sua extensão e uma estimativa de 309 mil passageiros, também diários, valor este que corresponde a um valor de $30 \%$ de faixas exclusivas para cada 100.000 habitantes (IDEC, 2018).

As faixas analisadas no presente estudo, como a Rua XV de novembro, possui aproximadamente 2,5 Km de extensão, enquanto que, a faixa da Rua Marechal Deodoro possui $600 \mathrm{~m}$. Somadas atendem um total de 25 linhas do transporte coletivo da cidade de Curitiba, e, atendem 83 mil pessoas por dia, conforme indicado na Tabela 1:

Tabela 1 - Características físicas e operacionais dos corredores da Rua XV de novembro e da Rua Marechal Deodoro.

\begin{tabular}{ccc} 
Corredor & Rua XV & Marechal Deodoro \\
\hline Ano de inauguração & 2014 & 2015 \\
Extensão em $(\mathrm{km})$ & 2,5 & 0,6 \\
Demanda diária corredor $(\mathrm{m})$ & 53.000 & 30.000 \\
Demanda de Coletivos & 12 & 13 \\
\hline Corredor & Rua XV & Marechal Deodoro \\
\hline Possibilidade de ultrapassagem & Não & Não \\
Paradas na extensão das faixas & 10 & 3 \\
Limite de velocidade permitida $(\mathrm{Km} / \mathrm{h})$ & 50 & 50 \\
\hline
\end{tabular}

Fonte: Elaboração própria. 
A Figura 6 mostra o gráfico com o tempo de redução nas viagens em percentuais, números consideráveis para a extensão da faixa exclusiva na Rua XV de novembro. Foram constatados no estudo de redução do tempo de viagem um ganho operacional em média de $44,5 \%$ no trecho percorrido na faixa exclusiva.

Figura 6 - Gráfico com tempo de Reduções de linha.

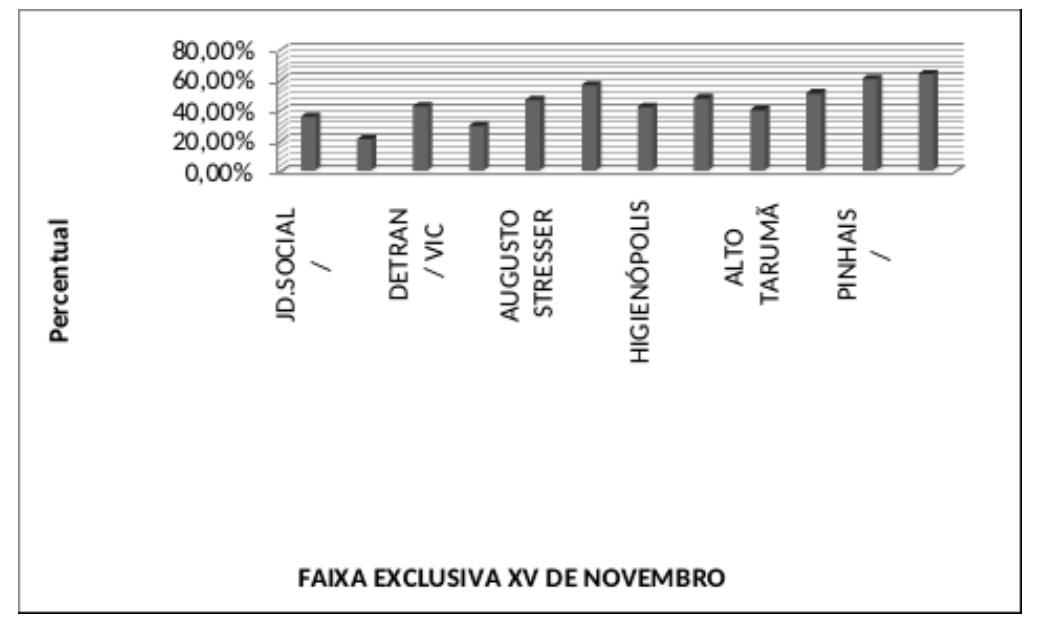

Fonte: Elaboração própria.

Assim como a Figura 6, a Figura 7 indica o gráfico com o tempo de redução nas viagens, todavia para a extensão da faixa exclusiva na via Marechal Deodoro. Foram constatados no estudo de redução do tempo de viagem um ganho operacional em média de $18,4 \%$ no trecho percorrido na faixa exclusiva.

Figura 7 - Gráfico com tempo de Reduções de linha.

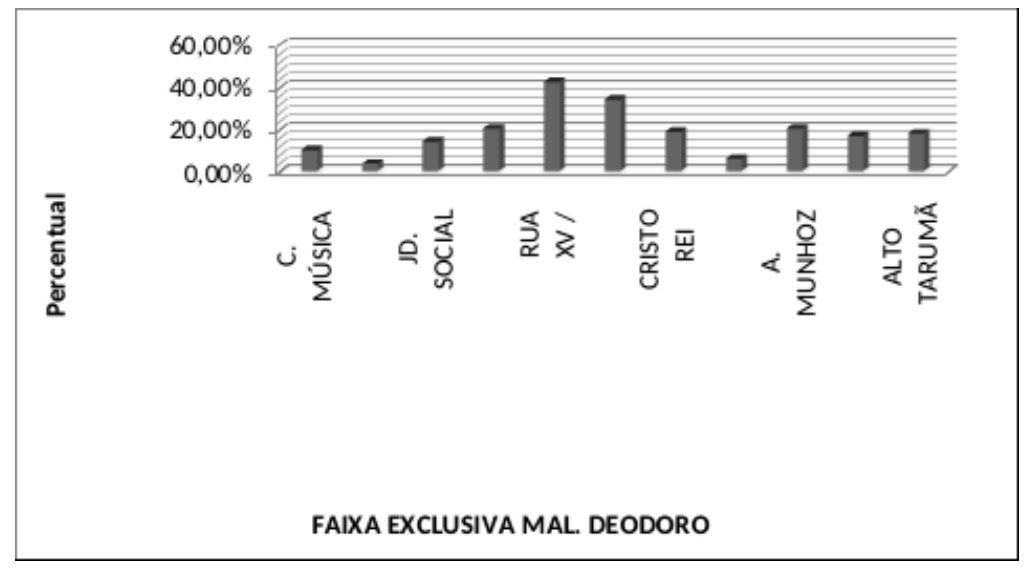

Fonte: Elaboração própria. 
Por intermédio da Tabela 2 é possível observar que a linha de ônibus que teve uma maior redução no trecho foi a linha Inter hospitais, com $63,35 \%$. Na Tabela 3, esta evidenciado que a linha com maior redução foi a linha Rua XV/Barigui com 42,23\%. Isto representa que a redução na linha Inter hospitais foi considerável, entretanto, devemos considerar sua extensão, logo que, esta linha possui 18,016 Km e, utiliza somente $1,125 \mathrm{Km}$ de uso da faixa ou seja, um aproveitamento de apenas de $6 \%$ de todo seu potencial. Já a linha Rua XV/Barigui tem sua extensão limitada em 32,005 Km, portanto, utiliza somente $0,6 \mathrm{Km}$ de sua faixa, ou seja, um aproveitamento de $3 \%$.

Tabela 2 - Corredor da Rua XV de novembro.

\begin{tabular}{|c|c|c|c|}
\hline Linha & $\begin{array}{l}\text { Extensão } \\
\qquad(\mathrm{Km})\end{array}$ & $\begin{array}{l}\text { Redução no trecho } \\
(\%)\end{array}$ & $\begin{array}{l}\text { \% faixa } \\
\text { Utilizada }\end{array}$ \\
\hline Jd. Social/Batel & 20,925 & $35,29 \%$ & $4 \%$ \\
\hline Rua XV/Barigui & 20,354 & $20,64 \%$ & $4 \%$ \\
\hline Detran/Vic. Machado & 22,06 & $42,33 \%$ & $12 \%$ \\
\hline C.imbuia/PQ. Barigui & 32,005 & $29,46 \%$ & $8 \%$ \\
\hline Augusto Stresser & 18,651 & $46,36 \%$ & $5 \%$ \\
\hline Hugo Lange & 18,057 & $56,30 \%$ & $5 \%$ \\
\hline Higienópolis & 17,327 & $41,80 \%$ & $15 \%$ \\
\hline Tarumã & 20,21 & $47,54 \%$ & $13 \%$ \\
\hline Alto Tarumã & 18,39 & $39,78 \%$ & $14 \%$ \\
\hline Sagrado Coração & 21,035 & $50,83 \%$ & $12 \%$ \\
\hline Pinhais/Guadalupe & 19,903 & $60,28 \%$ & $6 \%$ \\
\hline Inter hospitais & 18,016 & $63,35 \%$ & $6 \%$ \\
\hline $\begin{array}{c}\text { Redução média no tempo de } \\
\text { viagem }\end{array}$ & - & $44,50 \%$ & - \\
\hline
\end{tabular}

Fonte: Elaboração própria. 
Tabela 3 - Faixa Exclusiva Rua Marechal Deodoro.

\begin{tabular}{cccc}
\hline Linha & $\begin{array}{c}\text { Extensão } \\
(\mathbf{K m})\end{array}$ & $\begin{array}{c}\text { Redução no trecho } \\
\mathbf{( \% )}\end{array}$ & $\begin{array}{c}\text { \% faixa } \\
\text { Utilizada }\end{array}$ \\
\hline Novena & 14,227 & $10,06 \%$ & $4 \%$ \\
Jd. Social/Batel & 6,885 & $3,61 \%$ & $9 \%$ \\
Itupava/Hosp. Militar & 11,042 & $14,11 \%$ & $5 \%$ \\
Rua XV/Barigui & 15,639 & $20,20 \%$ & $4 \%$ \\
Detran/Vic. Machado & 20,354 & $42,23 \%$ & $3 \%$ \\
Cristo Rei & 22,06 & $33,78 \%$ & $3 \%$ \\
Cajuru & 11,143 & $18,63 \%$ & $5 \%$ \\
Tunhoz/Jd. Botânico & 19,778 & $5,85 \%$ & $3 \%$ \\
Tarumã & 17,906 & $20,24 \%$ & $3 \%$ \\
Alto tarumã & 20,21 & $16,67 \%$ & $3 \%$ \\
\hline Redução média no tempo de & 18,39 & $17,86 \%$ & $3 \%$ \\
\hline
\end{tabular}

Fonte: Elaboração própria.

Realizando uma comparação entre todas as linhas que utilizam o corredor em sua extensão, pode ser observado que o ganho de tempo é somente razoável, uma vez que após o término das faixas a um retorno ao trânsito o que volta a saturar a viagem do transporte coletivo, conforme indicado na Tabela 4: 
Tabela 4 - Faixa exclusiva Marechal Deodoro e rua XV de novembro.

\begin{tabular}{cccc}
\hline Linha & $\begin{array}{c}\text { Antes da implantação } \\
\mathbf{1 1 / 0 3 / 2 0 1 5}\end{array}$ & $\begin{array}{c}\text { Verificação } \\
\mathbf{2 5 / 0 3 / 2 0 1 5}\end{array}$ & $\begin{array}{c}\text { Verificação } \\
\mathbf{0 1 / 0 3 / 2 0 1 5}\end{array}$ \\
\hline Novena & $00: 02: 59$ & $00: 02: 41$ & $00: 02: 41$ \\
C. Música/V. Alegre & $00: 02: 46$ & (Falha GPS) & $00: 02: 40$ \\
Jd. Social/Batel & $00: 04: 08$ & $00: 03: 03$ & $00: 03: 33$ \\
Itupava/Hosp. Militar & $00: 05: 07$ & $00: 03: 48$ & $00: 04: 05$ \\
Rua XV/Barigui & $00: 04: 56$ & $00: 03: 00$ & $00: 02: 51$ \\
Detran/Vic. Machado & $00: 03: 45$ & $00: 02: 41$ & $00: 02: 29$ \\
Cristo Rei & $00: 04: 23$ & $00: 05: 08$ & $00: 03: 34$ \\
Cajuru & $00: 03: 08$ & $00: 04: 07$ & $00: 03: 19$ \\
Tarumã & $00: 02: 48$ & $00: 02: 04$ & $00: 02: 14$ \\
Alto tarumã & $-00: 04: 00$ & $00: 04: 00$ & $00: 03: 20$ \\
\hline
\end{tabular}

Fonte: Elaboração própria. 
Tabela 5 - Corredor da Rua XV de novembro.

\begin{tabular}{cccc}
\hline Linha & $\begin{array}{c}\text { Antes da implantação } \\
\mathbf{1 1 / 0 4 / 2 0 1 4}\end{array}$ & $\begin{array}{c}\text { Verificação } \\
\mathbf{2 5 / 0 7 / 2 0 1 4}\end{array}$ & $\begin{array}{c}\text { Verificação } \\
\mathbf{2 9 / 0 8 / 2 0 1 4}\end{array}$ \\
\hline Jd. Social/Batel & $00: 04: 49$ & $00: 03: 07$ & $00: 01: 31$ \\
Rua XV/Barigui & $00: 06: 47$ & $00: 05: 23$ & $00: 04: 51$ \\
Detran/Vic. Machado & $00: 13: 02$ & $00: 07: 31$ & $00: 08: 30$ \\
C.imbuia/Pq. Barigui & $00: 12: 37$ & $00: 08: 54$ & $00: 09: 44$ \\
Augusto Stresser & $00: 10: 04$ & $00: 05: 24$ & $00: 05: 06$ \\
Hugo Lange & $00: 11: 15$ & $00: 04: 55$ & $00: 05: 10$ \\
Higienópolis & $00: 14: 38$ & $00: 08: 31$ & $00: 07: 27$ \\
Tarumã & $00: 14: 35$ & $00: 07: 39$ & $00: 07: 53$ \\
Alto Tarumã & $00: 15: 00$ & $00: 09: 02$ & $00: 07: 55$ \\
Sagrado coração & $-00: 16: 02$ & $00: 07: 53$ & $00: 07: 10$ \\
Pinhais/Guadalupe & $-00: 09: 34$ & $00: 03: 48$ & $00: 03: 08$ \\
Inter hospitais & $00: 08: 52$ & $00: 03: 15$ & $00: 03: 30$ \\
\hline
\end{tabular}

Fonte: Elaboração própria.

Em todas as linhas o ganho em tempo equivale em média 58,0\% para um trecho de 3,1 Km. Este valor é considerável em linhas com maior quilometragem, de tal modo que se houvesse uma maior extensão de faixas o ganho seria superior no tempo de redução das linhas.

\subsection{Análise crítica do sistema}

Foram observados alguns pontos pertinentes a engenharia de tráfego quanto à faixa exclusiva, para que de fato sua eficácia seja efetivamente comprovada. Adaptações como sistemas inteligentes de programação semafórica são de grande relevância nesta abordagem, como exemplo, a onda verde (URBS. 2018). 
A educação dos condutores para espaços compartilhado no trânsito é um dos grandes desafios encontrados nas cidades que implementaram o sistema de faixas exclusivas para o transporte coletivo, no qual, ainda existe um desrespeito proveniente dos próprios condutores. Para Monteiro (2014), os usuários de automóveis ainda não estão prontos para a redução dos espaços para a circulação individual e, por isso, tentarão sempre burlar a regulamentação da operação de faixas exclusivas.

Dado o exposto, deve-se orientar a população sobre os benefícios que trarão medidas como fiscalização eletrônica e outros limitadores físicos. Vale ressaltar que, estes aspectos tendem a contribuir tanto para segurança dos próprios usuários da via, quanto principalmente, dos pedestres que neste trecho circulam.

As críticas no desempenho do transporte coletivo após a implantação da faixa exclusiva têm demonstrado que os trechos podem ser mais abrangentes no itinerário das linhas. O que vem de encontro é a necessidade de faixas compartilhadas maiores, de tal modo que proporcione um maior ganho de velocidade operacional, principalmente em horários “de pico” $\left(\mathrm{HMM}^{7}\right)$ horário de maior movimento.

\section{CONCLUSÃO}

Este trabalho teve como principal objetivo analisar os possíveis impactos da implantação de um projeto de faixa exclusiva para ônibus no Município de Curitiba (PR). A intenção do projeto é priorizar o transporte público, tornando-o mais rápido e eficiente, consequentemente mais atrativo para a população, motivando a mudança de modal de automóvel para o transporte público.

Gestores e engenheiros de transportes têm realizado estudos para identificar os problemas de evasão do transporte público, uma vez que no decorrer dos últimos anos, observou-se redução no número de passageiros. As análises apontaram como item principal a velocidade de deslocamento dos automóveis em relação aos ônibus, ficando estes a desejar no quesito tempo de percurso carro versus ônibus.

As faixas exclusivas vieram como uma possibilidade de melhoria no tempo de deslocamento, viabilizando ao transporte coletivo maior velocidade operacional, tornando desta forma uma opção viável para os condutores de automóveis, incentivando-os a mudança de modal. Como as mudanças não 
se limitam ao trânsito, é necessário verificar todas as condicionantes para projetar o transporte público dentro de parâmetros aceitáveis a crescente demanda de passageiros.

Fora observado ainda que o interesse nos deslocamentos para mudança, seria necessário que o transporte coletivo tenha velocidade não inferior ao dobro do realizado pelo automóvel. Portando justificando cada vez mais alternativas que possam contribuir na redução de velocidade operacional.

Após a implantação das faixas exclusivas, os estudos demonstraram que a eficiência deste projeto poderia ser melhor, uma vez que as faixas implantadas abrangem cerca de $3 \mathrm{Km}$ de extensão, sendo que os resultados são menores que as expectativas apontadas. Não bastam apenas as faixas, é necessário à mobilidade urbana intervenções em todas as situações que norteiam o transporte coletivo.

Estas medidas abrangem reestruturação de vias, planejamento horário para atividades públicas, inserção da bilhetagem única, ações de distribuição de demanda por faixa horária, com redução tarifária. Deste modo é possível proporcionar maior incentivo para os usuários utilizarem o transporte coletivo que hoje está com em constante competitividade com novas tecnologias no mercado da mobilidade, fato este que impacta diretamente a utilização do transporte coletivo.

Outras ações que devem ser discutidas são em relações a falta de algumas estruturas que influenciam na perca de tempo e na qualidade do transporte que utilizam as vias exclusivas para o ônibus. Estas medidas podem ser diagnosticadas com estudos pontuais que visam a melhoria.

Exemplos que podem ser citados tais como intervenções semafóricas, em que o motorista possa emitir alertas em determinados trechos para que se tenha prioridade no transporte coletivo em relações aos automóveis, uma melhora do que pode diminuir o tempo de viagens e gerar menos atrasos que poderiam evitar o comboio de ônibus. Outras menções podem ser feitas a padronizar metodologias em relações aos custos das faixas implantadas, uma vez que algumas recebem material de baixa durabilidade o que vem a aumentar o custo de manutenção.

Por fim a implantação de uma faixa exclusiva é de grande importância, uma vez que impacta diretamente no bem comum da sociedade. Deve-se também garantir o direito de um indivíduo de se 
deslocar na cidade onde vive de forma confortável, rápida e com qualidade.

\section{Referências}

ALLIARDI, E. Mobilidade urbana de Cachoeirinha: Impactos de uma faixa exclusiva de ônibus. 2016. Disponível em: https://www.lume.ufrgs.br/handle/10183/148726. Acesso em: 7.mai.2019.

AUGUSTO, E. Panorama do Sistema de Transporte Público em Curitiba - PR, 2015. Disponível em: https://www.mobilize.org.br/midias/pesquisas/panorama-do-sistema-de-transporte-em-curitiba.pdf. Acesso em: 3.mai.2019.

BARAT, F. Estrutura metropolitana e sistema de transportes: Estudo de Caso. Rio de Janeiro: Editora IPEA/INPES, 1975.

BRASIL. Ministério das Cidades. Secretaria Nacional de Transporte e da Mobilidade Urbana. Manual do BRT: Guia de planejamento. Brasília, DF, 2007.

FREIRE, S.A; MONTENEGRO, A.P; PANET, M.F; ALVES, L.C; SILVA, F.J. Mobilidade urbana sustentável: Uma avaliação do sistema integrado de transporte público coletivo na cidade de João Pessoa. In: Encontro Nacional de Tecnologia do Ambiente Construído, 13, 2010.

GAZETA DO POVO. Linha Verde ainda mantém cara de rodovia. 2010. Disponível em: https://www.gazetadopovo.com.br/vida-e-cidadania/linha-verde-ainda-mantem-cara-de-rodovia4d1g9x9bilcj1bhfxm923ygla/. Acesso em: 4.mai.2019.

GOMIDE, A.P. Transporte coletivo urbano em Uberlândia: a questão tarifária. In: $5^{\circ}$ PRÊMIO MINAS DE ECONOMIA, 1992, Categoria Universitário. Belo Horizonte: BDMG, 1993.

IDEC. Análise das infraestruturas de priorização do transporte coletivo sobre pneus nas 12 capitais mais populosas do Brasil. 2018. Disponível $\mathrm{em}: \underline{\mathrm{htt}} \underline{\mathrm{ss}}$ //idec.org.br/sites/default/files/relatorio_pesquisa de_prioridade nas vias.pdf Acesso em 20.Jun.2019.

IPPUC. Eixo estrutural de Curitiba (Sem ano). Disponível em: http://www.ippuc.org.br/mostrarlinhadotempo.php?pagina=12. Acesso em: 3 mai. 2019.

MIRANDA, F.H. Mobilidade Urbana Sustentável e o caso de Curitiba. 2010. Disponível em: http://www.teses.usp.br/teses/disponiveis/18/18144/tde-03052011-103404/en.php. $\quad$ Acesso em: 1.mai.2019. 
MONTEIRO, R, M. BRT ou faixa exclusiva para ônibus: Qual opção permite mais ganhos ao usuário. 2014. Disponível em: http://www.perkons.com/pt/noticia/1549/brt-ou-faixa-exclusiva-para-onibus-qualopcao-permite-mais-ganhos-aos-usuarios. Acesso em: 5.jun.2019.

OBA, L.T. Curitiba e seus eixos estruturais, II encontro anual Associação Nacional de Pós-Graduação e Pesquisa em Ambiente e Sociedade, 2004. Disponível em: http://www.anppas.org.br/encontro anual/encontro2/GT/GT14/leonardo oba.pdf. $\quad$ Acesso em: 3 mai.2019.

PMC - PREFEITURA MUNICIPAL DE CURITIBA. Sistema viário organizou a cidade e induziu o desenvolvimento de Curitiba, 2015. Disponível em: http://www.curitiba.pr.gov.br/noticias/sistemaviario-organizou-a-cidade-e-induziu-o-desenvolvimento-de-curitiba/37925. Acesso em: 5.mai.2019.

SILVA, A.G.; ANNA, S.A.J. Análise dos Aspectos Qualitativos de Vias Exclusivas em Sistemas Modernos de Ônibus, 2006. Disponível em: < http://www.ig.ufu.br/revista/caminhos.htmle. >Acesso em: 6.mai.2019.

SILVA, M.D. Análise da Variabilidade do Tempo de Viagem Sistemas Bus Rapid Transit (BRT), 2015. Disponível em: http://hdl.handle.net/10183/127810. Acesso em: 5.jun.2019.

STIEL, W.C. História do Transporte Urbano no Brasil. Ed. Única. Brasília EBTU Empresa Brasileira de Transportes. Editora Pini, 1984.

URBS. Transporte Curitibano. 2012. Disponível em: < https://www.urbs.curitiba.pr.gov.br/noticia/transporte-de-curitiba >. Acesso em: 01.out.2019.

$\begin{array}{lllll}\text { URBS. } & \text { Composição } & \text { de } & \text { frotas. }\end{array}$ $<$ https://www.urbs.curitiba.pr.gov.br/transporte/rede-integrada-de-transportee. $\quad>\quad$ Acesso em: 19.mai.2019.

\section{Notas de Rodapé}

7. H.M.M. - Horário de Maior Movimento. 